\title{
Autonomia moral na obra de Jean Piaget: a complexidade do conceito e sua importância para a educação
}

\section{Moral autonomy in Jean Piaget works: the complexity of concept and it's importance to education}

\author{
Lia Beatriz de Lucca Freitas*
}

\begin{abstract}
RESUMO
Os resultados de uma pesquisa qualitativa realizada com professoras de escolas infantis da cidade de Porto Alegre (RS), cuja ação educativa fundamenta-se na teoria piagetiana, mostraram uma compreensão bastante superficial do conceito de autonomia moral. O principal objetivo deste artigo é esclarecer o conceito de autonomia moral na teoria piagetiana, visto que este conceito é muito importante quando se trata de educação. Segundo Piaget, o fim da educação deveria ser a autonomia. Dois aspectos são abordados: 1) como a constituição da consciência moral autônoma se constitui, para Piaget, em um problema a ser investigado e 2) o processo de construção da autonomia moral ao longo do desenvolvimento. Busca-se enfatizar a importância da ação educativa na conquista da autonomia moral pelo ser humano.

Palavras-chave: Ética, construtivismo, desenvolvimento moral.
\end{abstract}

\begin{abstract}
The results of a qualitative research showed little understanding of the concept of moral autonomy. Participants were teachers of nursery scholls

*Doutora em Psicologia Universidade Federal do Rio Grande do Sul.
\end{abstract} lfreitas@psico.ufrgs.br 
in Porto Alegre (RS) where educational methods were based on Piaget's theory. The principal aim of this paper is the explanation of Piaget's concept of moral autonomy. This concept is very important to educators since Piaget says that the purpose of education should be the autonomy. Our approach includes: 1- how the construction of moral autonomy became a problem to be investigated by Piaget; 2 - the process of constructing moral autonomy through human development. We try to enphasize importance of education for the human being to achive moral autonomy.

Key-words: Ethics, constructivism, moral development.

\section{Introdução}

Não raras vezes, quanto mais divulgadas são as idéias de um autor, menos elas são compreendidas. Esse parece ser o caso de Jean Piaget. Muitas páginas foram escritas para criticá-lo e outras tantas para defendê-lo (ver, por exemplo, Lourenço e MACHADO, 1996). Vários autores dedicaram-se a refletir sobre o porquê dos mal-entendidos ocorridos no processo de divulgação de seu pensamento, sobretudo, mas não exclusivamente, no meio educacional. Entre as diversas razões apresentadas, gostaríamos de destacar as seguintes: a obra de grandes pensadores está sujeita a curiosos erros de interpretação (RAmozzi-Chiarottino, 1988); a forma como a teoria piagetiana foi "assimilada" no meio educacional brasileiro, em função de contigências históricas (VASCOLCELOS, 1997); nos cursos de formação, trabalha-se apenas a "parte aparente" da teoria piagetiana, isto é, os estágios do desenvolvimento cognitivo (Perraudeau, 1998).

Neste trabalho, vamos nos dedicar a uma tarefa mais singela, mas não de menor valor, que é a de esclarecer um conceito diversas vezes referido, mas pouco compreendido: o conceito de autonomia moral. No campo educacional, isso reveste-se de grande importância, na medida em que, segundo Piaget, o fim da educação seria a autonomia - ao mesmo tempo intelectual e moral - visto que se o ser humano "é passivo intelectualmente, ele não será moralmente livre” (PIAGET, 1988, p. 90). Esperamos, dessa forma, contribuir com educadores, reeducadores e psicólogos, sejam profisionais ou pesquisadores, cuja ação se inspira na teoria piagetiana e, dessa forma, socializar um conhecimento constituído ao longo de vários anos. 


\section{O que se entende por autonomia? - alguns dados de pesquisa}

Tendo constatado a existência de um certo mal-estar no que diz respeito à precariedade da compreensão das idéias de Piaget no meio educacional (esse mal-estar vem sendo sentido tanto por parte dos próprios educadores quanto por aqueles que com eles trabalham), AzEvEDo (2001) realizou uma pesquisa qualitativa sobre as relações que professoras de escolas infantis de Porto Alegre-RS estabelecem entre a sua prática educativa e a teoria piagetiana, com o intuito de apontar um caminho para a formação de professores. Não pretendemos, aqui, aprofundar as interessantes reflexões de AzEvedo (2001). Apresentamos alguns dados de sua pesquisa apenas como ponto de partida para o diálogo que buscamos estabelecer com aqueles que se interessam pelo pensamento de Jean Piaget.

As professoras que participaram do estudo de AzEVEDo (2001) não foram selecionadas aleatoriamente; pelo contrário, foram escolhidas porque atendiam aos seguintes critérios: 1) já ter concluído o curso de Pedagogia; 2) não exercer outra função além do magistério; 3) estar trabalhando em uma escola infantil, na qual a teoria piagetiana é a principal fonte inspiradora do trabalho educativo; 4) ter uma carga horária de trabalho que permita tempo para estudo e planejamento. Na coleta de dados, foram utilizados dois instrumentos: 1) um questionário preenchido pelas professoras sobre sua experiência profissional, situação funcional atual, formação acadêmica, cursos e leituras sobre a teoria piagetiana, o qual se baseou no instrumento elaborado por CARVALHO (2000); 2) entrevistas individuais semi-estruturadas, nas quais se conversava com a professora sobre o trabalho realizado cotidianamente com seus alunos.

Para ilustrar o que essas professoras entendiam por autonomia, selecionamos os seguintes extratos de entrevista:

A autonomia, para mim, é exatamente a criança que sabe se virar. A heteronomia é quando a criança... ela necessita ainda a orientação do professor.

Por exemplo, se ela derrama lá o suco. Ah! Tem crianças que já sabem: Bom, derramou o suco o que eu vou fazer? Eu vou lá, eu vou pegar o pano e eu vou limpar. E tem umas que ficam: - E agora? O que eu faço? Então, tu ajudas a criança: - Bem, o que tu achas que tem que fazer? Ah! Tem que limpar. - Então vamos lá. Esses seriam dois exemplos: um de heteronomia e um de autonomia. 
Evidentemente, não podemos generalizar esses dados, os quais, no entanto, nos indicam que a palavra autonomia tem sido entendida como sinônimo de independência. Ora, tal acepção quase nada conserva da complexidade do conceito de autonomia que encontramos nos textos escritos por Piaget. Cabe-nos não esquecer que a palavra autonomia tem significados distintos em diferentes teorias e, como sabemos, diferentes concepções dão origem a práticas diversas.

\section{O conceito de autonomia moral na obra de Jean Piaget}

Segundo alguns críticos de Piaget, coisas muito distintas teriam sido incluídas no conceito de autonomia. De fato, podemos ter essa impressão quando nos restringimos à leitura de $O$ julgamento moral na criança, que se tornou um clássico na área da psicologia da moral e é, segundo KesselRing (1993), um de seus livros mais conhecidos. Infelizmente, temos observado que mesmo entre os estudiosos, na maioria das vezes, a referência aos escritos de Piaget sobre a questão moral limita-se a esse livro. Acreditamos, porém, que para compreender-mos o que significa autonomia moral e qual o lugar da educação na constituição da consciência moral autônoma, é preciso considerar o conjunto de sua obra. Aliás, como bem lembrou RAMOzZIChiarottino (1998), o desprezo pela relação entre o todo e as partes é contrário às idéias de nosso autor. Partiremos, então, de uma passagem do livro Para onde vai a educação? e buscaremos esmiuçar o que está dito nessas linhas.

Com efeito, é essencial compreender que, se a criança traz consigo todos os elementos necessários à elaboração de uma consciência moral ou "razão prática", como de uma consciência intelectual ou razão, simplesmente, nem uma nem outra são dadas prontas no ponto de partida da evolução mental e uma e outra se elaboram em estreita conexão com o meio social: as relações da criança com os indivíduos dos quais ela depende serão, portanto, propriamente falando formadoras, e não se limitarão, como geralmente se acredita, a exercer influências mais ou menos profundas, mas de alguma maneira acidentais em relação à própria construção das realidades morais elementares. (Piaget, 1988, p. 95) 
Antes de mais nada, é preciso lembrar que Piaget dedicou a maior parte de sua vida a explicar como é possível ao homem alcançar o conhecimento. No entanto, em um estudo sobre o projeto inicial de Piaget acerca da moral (FreItAS, 1998), constatamos que além de construir uma teoria do conhecimento, ele aspirava estabelecer uma teoria sobre a moral. Ambos os projetos se encontram já em Recherche (PiAgET, 1918).

Para Piaget, o conhecimento é possível graças ao funcionamento daquilo que ele chamou de "estruturas mentais" e que os filósofos denominam "razão". Porém, tais estruturas não são inatas; o que existe no genoma são possibilidades próprias da espécie humana, as quais poderão ou não ser concretizadas. Para que essas possibilidades se concretizem é necessário que ocorram trocas com o meio físico e social, sendo essas trocas, portanto, propriamente falando, "formadoras" - diz Piaget (1988). Ele procurou por um lado explicar como funcionam essas estruturas e de outro, como essas estruturas são construídas nas trocas incessantes entre o organismo e o meio (RAMOzzIChiarottino, 1997). Os tão divulgados estágios do desenvolvimento cognitivo - sensório-moto, pré-operatário, operatório concreto e operatório formal nada mais são que o caminho a ser percorrido por qualquer indivíduo da espécie humana na construção das estruturas mentais (o que não quer dizer que todos os indivíduos percorram todo esse caminho, e muito menos no mesmo ritmo). É a existência desse longo processo construtivo que explicaria a ausência da possibilidade de raciocínio lógico na criança pequena, bem como a possibilidade de pensamento lógico no adulto.

Embora Piaget tenha desenvolvido um menor número de estudos no campo da moral, ele procurou fazer o mesmo nesse domínio: explicar como a partir do mundo amoral do bebê é possível ao ser humano constituir uma consciência moral autônoma (FREITAS, 1999). Ele herdou sobretudo de BovET (1912) a idéia de que o estabelecimento de trocas interindividuais é condição necessária para a concretização desse processo. Novamente, as trocas com o outro são, para Piaget (1988), formadoras e "não se limitam a exercer influências mais ou menos profundas..." 


\section{A consciência moral autônoma: um problema a ser investigado}

Em seus estudos sobre a constituição da consciência moral, PIAGET (1992) inspira-se, em grande medida, em um estudo de воvEт (1912) sobre as condições da consciência de obrigação, isto é, as condições necessárias para que o sujeito sinta que deve (ou não deve) agir de uma determinada maneira, condição sine qua non de uma vida moral. Segundo Bovet (1912), duas condições são necessárias e juntas, suficientes para que surja a consciência de obrigação no sujeito: 1) que uma consigne seja dada; 2) que essa consigne seja aceita por aquele que a recebe. Ele definiu uma consigne como uma ordem ou proibição: 1) dada sem indicação precisa nem de motivos nem de sanções; 2) válida até novo aviso; 3) que diz respeito a um ato subordinado a circunstâncias exteriores que devem ser reconhecidas pelo sujeito. ${ }^{1}$ Para que uma consigne seja aceita, o seu autor deve ter prestígio ou autoridade aos olhos daquele que a recebe, ou seja, deve existir uma relação de respeito. Piaget percebe, no entanto, uma limitação na tese de Bovet: "como, se todo dever emana de personalidades superiores a ela, a criança adquirirá uma consciência autônoma?" (PIAGET, 1992, p. 308). Em suas pesquisas, ele busca uma resposta a essa pergunta. PIAGET (1992) encontra no jogo de regras um terreno propício para o estudo da questão de como é possível a aquisição de uma consciência autônoma. As regras do jogo, como as regras morais - diz ele - "se transmitem de geração em geração e se mantêm unicamente graças ao respeito que os indivíduos têm por elas" (p. 2). Todavia, há uma diferença essencial: enquanto as normas morais são impostas pelos adultos, as regras do jogo, pelo contrário, são elaboradas apenas pelas crianças. $\mathrm{O}$ fato de que essas regras não têm um conteúdo moral propriamente dito não era relevante para ele, visto que "os deveres não são obrigatórios por causa de seu conteúdo, mas pelo fato de emanarem de indivíduos respeitados" (PIAGET, 1992, p. 311).

Em contrapartida, se, como dissera BOVET (1912), a consciência de obrigação supõe uma relação entre, no mínimo dois indivíduos, interessava a PIAGET

1 BOVET (1912) diz que utilizou a palavra consigne para traduzir para o francês a palavra alemã Aufgabe. Em geral consigne tem sido traduzida para o português como "ordem". Nós preferimos manter a palavra consigne e apresentar a definição dada por Bovet a essa palavra. 
(1992) estudar os diferentes tipos de relação estabelecida, ou melhor dito, os efeitos dos diferentes tipos de relação social na constituição da consciência moral da criança. Ele distingue dois tipos básicos de relação social a coação social e a cooperação - e chama de coação social "toda relação entre dois ou $n$ indivíduos na qual não intervém um elemento de autoridade ou de prestígio"; cooperação é "toda relação entre dois ou $n$ indivíduos iguais ou que se crêem iguais, dito de outra forma, toda relação social na qual não intervém nenhum elemento de autoridade ou de prestígio" (PIAGET, 1977, p. 225-226).

PIAGET (1992) encontra na comunidade de pequenos jogadores - na qual a influência do mundo adulto é bastante reduzida - uma coletividade de iguais. Os resultados de suas pesquisas sobre as regras do jogo evidenciam uma dualidade na forma de sentir e de se conduzir, a qual ele relaciona à tese kantiana da existência de duas morais: a moral da heteronomia e a moral da autonomia. Além disso, ele levanta a hipótese de que existiria no ser humano um processo evolutivo que iria da primeira em direção à segunda. Essa hipótese foi corroborada mediante os seus estudos sobre os efeitos da coação social e da cooperação na formação da consciência moral do sujeito, os quais se encontram, respectivamente, nos capítulos 2 e 3 de $O$ julgamento moral na criança.

\section{A constituição da consciência moral autônoma}

Até por volta de $1 \frac{1}{2}-2$ anos, não há normas, apenas regularidades espontâneas, as quais não são sentidas como obrigatórias. Em função disso, Piaget denominou "anomia" esse primeiro período do desenvolvimento moral do ser humano. Por que não há normas nesse momento? Embora desde muito cedo possamos observar reações afetivas da criança em relação às pessoas, é apenas por volta de $1 \frac{1 / 2}{2}-2$ anos que ocorre uma primeira diferenciação sujeito-objeto (eu-outrem), conforme nos mostrou PIAGET (1967) em A construção do real na criança, a qual é condição necessária para que ocorram trocas interindividuais propriamente ditas.

$\mathrm{Na}$ medida em que a criança estabelece as primeiras relações interindividuais com adultos significativos para ela (pais, professores etc.), as normas passam a ser sentidas como obrigatórias - sejam estas regras relativas a hábitos, regras do jogo ou preceitos morais -, em função da relação de respeito 
que se estabelece entre a criança e esses adultos. Isso não ocorre com qualquer adulto, mas apenas com pessoas com as quais a criança tem um vínculo afetivo. É comum uma criança rejeitar uma ordem dizendo: "Tu não és minha mãe!" ou "Tu não és minha professora!". Muitos confundem esse tipo de respeito, que PIAGET (1992) denominou "unilateral", com desrespeito e, em função disso, atribuem-lhe um valor negativo. Na verdade, ele chamou esse tipo de respeito de unilateral, porque a criança não dá ordens e nem prescreve normas de conduta ao adulto, e caso isso acontecesse, ele não se sentiria obrigado por elas. Evidentemente, o adulto também respeita a criança, mas em outro sentido: não lhe causa danos, considera seus desejos e necessidades etc.

Constitui-se, assim, a moral da heteronomia, na qual a norma que dita à consciência do sujeito se ele deve (ou não deve) fazer uma determinada ação provém do outro. Em sua pesquisa sobre as regras do jogo, PIAGET (1992) constatou uma atitude paradoxal: para a criança pequena, a regra é sagrada e imutável, mas na prática ela não a segue. Dócil em aparência "a criança não chega, realmente, senão a um simulacro da sociabilidade, para não dizer nada ainda da moralidade" (1992, p. 48). Além de ser insuficiente para transformar a conduta, a obediência produz conseqüências inopinadas, as quais deixam os adultos, muitas vezes, desconcertados. PIAGET (1992) verificou, por exemplo, que para a criança pequena uma mentira é tanto mais grave quanto mais a afirmação estiver em desacordo com a realidade, de maneira que ninguém possa acreditar nela. Temos, aqui, um belo exemplo de que no domínio moral, como no campo do conhecimento, não há jamais registro "puro", mas sempre atividade assimiladora do sujeito. Portanto, a ação educativa tem seus limites.

Esse tipo de moral predomina na criança, em função da assimetria própria de sua relação com os mais velhos. ${ }^{2}$ Ao contrário do que muitos pensam, essa é uma etapa de fundamental importância para o desenvolvimento moral: é no quadro preparado pelo respeito unilateral que formas superiores de respeito se tornam possíveis. Dito de outra maneira, o respeito unilateral é condição necessária (embora não suficiente) para que se construam formas superiores de respeito. Além disso, quando os adultos impõem à criança certos valores como devendo ser respeitados, ela pode compartilhar os valores de sua cultura e, mais tarde, organizar a sua própria escala de valores.

2 Encontra-se, porém, a moral da heteronomia também no adulto, quando ele permanece criança. 
Uma das grandes descobertas de PIAGET (1992) é a de que "com a idade o respeito muda de natureza" (p. 79). Na medida em que a criança estabelece trocas com outras crianças, que o seu desenvolvimento cognitivo lhe permite se descentrar de seu próprio ponto de vista e que, mais tarde, as diferenças de idade entre gerações deixam de ser relevantes, um outro tipo de relação se torna possível: a cooperação (no sentido etimológico da palavra, co-operação). Nas relações cooperativas, o respeito unilateral dá lugar ao respeito mútuo ou recíproco, graças ao qual abre-se o caminho para a conquista da autonomia moral pelo sujeito. Há autonomia moral quando a consciência considera como necessário um ideal como, por exemplo, a justiça, a liberdade... independentemente de qualquer pressão exterior. "A autonomia só aparece com a reciprocidade, quando o respeito mútuo é bastante forte para que o indivíduo experimente interiormente a necessidade de tratar os outros como ele gostaria de ser tratado." (PIAGET, 1992, p. 155)

Em seu estudo sobre as regras do jogo, PIAGET (1992) constatou que, em um determinado momento (por volta dos 7-8 anos, em média), a criança é capaz de seguir regras comuns a de seus companheiros e que há uma correlação evidente entre o momento em que a criança começa a seguir, efetivamente, as regras e o fato dela admitir que elas podem ser mudadas, sem que isso constitua uma transgressão. Ele chamou de autonomia a capacidade do sujeito de propor normas próprias. "Esta noção de autonomia é empregada aqui sem conotação filosófica. Ela designa apenas a possibilidade do sujeito de elaborar, ao menos em parte, suas próprias normas" esclarece PIAGET (1954, p. 534). A descoberta de sua capacidade de instituir normas, por parte do sujeito, é um primeiro passo em direção à autonomia moral, visto que ele compreende, então, que as normas sociais e os costumes, assim como as regras do jogo, modificam-se com o tempo, variam de grupo para grupo etc. Isso não significa, é claro, que a criança, a partir desse momento, se conduza apenas por normas que ela mesma elaborou. Todavia, a maneira como ela avalia e aplica os preceitos ditados por seus pais, professores e pela sociedade em geral difere daquela da moral da heteronomia: as faltas morais passam a ser julgadas em função da intenção do agente (e não mais em função de suas consequiências) e nem tudo que é determinado pelo adulto é considerado justo. Em síntese, o que queremos assinalar é que PIAGET (1992) fez uma importante descoberta: é no seio das relações de simpatia, de amizade, que surge um outro tipo de sentimento de obrigação. Assim como o respeito unilateral gera a obediência, o respeito mútuo ou recíproco não impõe senão a própria norma de reciprocidade, isto é, a obrigação de se colocar no ponto de vista do outro, de tratar o outro como gostaria de ser tratado. 
Todavia, se a reciprocidade fosse possível apenas "entre amigos", o ser humano estaria confinado aos restritos círculos que Piaget (1977) denominou as classes de co-valorisants, isto é, indivíduos que compartilham os mesmos gostos, opiniões e valores. Embora em $O$ julgamento moral na criança, Piaget já deixava claro que esse tipo de relação está fora da esfera moral, foi quase dez anos depois que estabeleceu, explicitamente, a diferença entre a reciprocidade espontânea e a reciprocidade normativa de ordem moral. Suas pesquisas empíricas no campo da moral não foram além das relações de amizade que se estabelecem, a cada geração, entre iguais. Essas relações são regidas por uma reciprocidade espontânea, a qual pode ser entendida como condição necessária para que a reciprocidade normativa de ordem moral seja possível. A reciprocidade nas relações de amizade é uma tendência espontânea do sujeito; na ação moral, uma obrigação. Em uma relação de respeito mútuo, o sujeito não pode, ao mesmo tempo, valorizar o outro e agir de maneira tal que seja desvalorizado por ele. Trata-se da norma de não contradição, no domínio moral. Conforme ressaltou o próprio Piaget $(1954$, p. 535), "tal é, pelo menos, a norma, da qual a moralidade de fato pode, evidentemente, afastar-se, da mesma forma que o pensamento comum pode afastar-se das regras de não contradição lógica." Para Piaget (1977) a essência da conduta ética é a coerência. Na vida social, porém, nem sempre é fácil ser coerente.

Um outro aspecto importante a ser esclarecido é que se, ao longo da gênese, o outro é uma determinada pessoa, uma vez a consciência moral autônoma constituída, o outro é o ser humano. Quando se atinge esse nível de desenvolvimento moral, respeitar uma pessoa significa atribuir à escala de valores do outro um valor equivalente ao de sua própria escala. Nesse caso, já não importa o conteúdo dos valores ou das convicções de cada um, mas sim o fato de se ter uma escala de valores. Todavia, conforme ressaltou PIAGET (1977, p. 186), "a consciência adulta autônoma é um produto social recente e excepcional." Em uma sociedade em que predominam os interesses de cada um e a competição destrutiva, é rara a liberdade própria do ser humano autônomo, o qual não se submete à tradição ou à opinião social vigente e tampouco se deixa dominar por suas fantasias subjetivas ou desejos imediatos. 


\section{Considerações finais}

Educar é uma atividade complexa: uma das descobertas humanas mais difíceis, conforme nos ensinou Kant. Assim sendo, não acreditamos que uma única teoria possa dar conta da arte de educar. No entanto, quando se elege uma teoria como parte do núcleo teórico que fundamenta uma determinada prática educativa, há conceitos que não podemos ignorar ou confundir com o senso comum.

Estamos inteiramente de acordo com Piaget (1965/1969) quando ele diz que "a psicologia pode multiplicar os dados de fatos e nossos conhecimentos sobre o mecanismo do desenvolvimento: esses fatos ou essas idéias não atingirão jamais a escola se os professores não os incorporarem até traduzi-los em realizações originais" (p. 168). Acreditamos que isso seja válido, na verdade, para todos aqueles que se ocupam dos problemas inerentes ao processo de socialização do ser humano. Cientes de que o rigor conceitual não é condição suficiente para que essas "realizações originais" sejam possíveis, é certo, porém, que conceitos mal compreendidos geram práticas equivocadas. Precisar conceitos é uma forma, então, de contribuir para que essas "realizações originais" sejam possíveis.

\section{REFERÊNCIAS}

AZEVEDO, C. Um caminho para a formação de professores. Porto Alegre, 2001. Dissertação (Mestrado) - Universidade Federal do Rio Grande do Sul.

BOVET, P. Les conditions de l'obligation de conscience. L'Anée Psychologique, tomo 18, p. 55-120, 1912.

CARVALHO, D. C. A relação entre psicologia e alfabetização sob a ótica dos professores. São Paulo, 2000. Tese (Doutorado) - Pontifícia Universidade Católica.

FREITAS, L. B. L. A moral na obra de Jean Piaget: um projeto inacabado. São Paulo, 1998. Tese (Doutorado) - Universidade de São Paulo.

FREITAS, L. B. L. Do mundo amoral à possibilidade de ação moral. Psicologia: reflexão e crítica, v. 12, n. 2, p. 447-458, 1999.

KESSELRING, T. Jean Piaget. Petrópolis: Vozes, 1993. 
LOURENÇO, O.; MACHADO, A. Defense of Piaget's theory: a reply to 10 common criticisms. Psychological review, v. 103, n. 1, p. 143-164, 1996.

PERRAUDEAU, M. Piaget hoje: respostas a uma controvérsia. Lisboa: Instituto Piaget, 1998.

PIAGET, J. Recherche. Lausanne: La Concorde, 1918.

PIAGET, J. Le jugement moral chez l'enfant. Paris: PUF, 1992. (Originalmente publicado em 1932).

PIAGET, J. La construction du réel chez l'enfant. Neuchâtel/Paris: Delachaux et Niestlé, 1967. (Originalmente publicado em 1937).

PIAGET, J. Essai sur la théorie des valeurs qualitatives en sociologie statique ("synchronique"). In: PIAGET, J. Études sociologiques. 3. ed., Genève: Droz, 1977, p. 100-142. (Originalmente publicado em 1941).

PIAGET, J. Les relations entre la morale et le droit. In: PIAGET, J. Études sociologiques. 3. ed., Genève: Droz, 1977, p. 172-202. (Originalmente publicado em 1944).

PIAGET, J. Les relations entre l'intelligence et l'affectivité dans le développement de l'enfant. Bulletin de Psychologie, tomo 7, p. 143-150, 346-361, 522-535 e 699-701, 1954.

PIAGET, J. Psychologie et pédagogie. Paris: Denoël/Gonthier, 1969. (Originalmente publicado em 1965).

PIAGET, J. Où va l'éducation? Paris: Denoë1/Gonthier, 1988. (Originalmente publicado em 1972).

RAMOZZI-CHIAROTTINO, Z. Psicologia e epistemologia genética de Jean Piaget. São Paulo: EPU, 1988.

RAMOZZI-CHIAROTTINO, Z. Organismo, lógica e sociedade no modelo piagetiano do conhecimento. In: FREITAG, B. (Org.). Piaget: 100 anos. São Paulo: Cortez, 1997. p. 111-122.

RAMOZZI-CHIAROTTINO, Z. Piaget selon l'ordre des raisons. Bulletin de Psychologie, tomo 51, n. 3, p. 333-342, 1998.

VASCONCELOS, M. S. Raízes e caminhos do pensamento piagetiano no Brasil. In: FREITAG, B. (Org.). Piaget: 100 anos. São Paulo: Cortez, 1997. p. 193-210.

Texto recebido em 10 de fev. 2002

Texto aprovado em 22 de abr. 2002 